\title{
Prospective European multicenter randomized trial of PleuraSeal for control of air leaks after elective pulmonary resection
}

\author{
Paul De Leyn, MD, PhD, ${ }^{a}$ Michael-Rolf Muller, MD, PhD, ${ }^{b}$ Jan Wolter A. Oosterhuis, MD, PhD, ${ }^{c}$ \\ Thomas Schmid, MD, ${ }^{\mathrm{d}}$ Cliff K. C. Choong, FRCS, FRACS, ${ }^{\mathrm{e}}$ Walter Weder, MD, ${ }^{\mathrm{f}}$ and Youri Sokolow, $\mathrm{MD}^{\mathrm{g}}$
}

Objectives: We sought to evaluate the efficacy and safety of a synthetic bioresorbable pleural sealant (PleuraSeal; Covidien, Bedford, Mass) to treat air leaks after pulmonary resection.

\begin{abstract}
Methods: Patients with air leaks after lung resection were randomized to treatment with pleural sealant on air leak sites after standard methods of lung closure or standard lung closure only. The primary outcome variable was the percentage of patients remaining air leak free until discharge. The secondary outcome variables were the proportion of patients with successful intraoperative air leak sealing, time to last air leak, and durations of chest tube drainage and hospitalization.
\end{abstract}

\begin{abstract}
Results: The sealant group comprised 62 subjects, and the control group comprised 59 subjects. Most patients $(98.3 \%)$ underwent open lobectomy for bronchogenic carcinoma. The overall success rates for intraoperative air leak sealing were as follows: sealant group, $71.0 \%$; control group, $23.7 \%(P<.001)$. For grade 2 and 3 air leaks $(\mathrm{n}=77)$, the intraoperative sealing rates were as follows: sealant group, $71.7 \%$; control group, $9.1 \%(P<.001)$. More patients with grade 2 and 3 air leaks had their leaks remain sealed in the sealant group (43.5\% vs $15.2 \%$, $P=.013$ ). The median time from skin closure to last observable air leak was 6 hours (sealant group) versus 42 hours (control group, $P=.718$ ). No treatment-related complications were reported. No differences in drainage or hospitalization were observed.
\end{abstract}

Conclusions: In this multicenter study the pleural sealant was safe and effective treatment for intraoperative air leaks after lung resection. Significantly fewer patients with surgically relevant intraoperative air leaks had postoperative air leaks when the pleural sealant was applied. (J Thorac Cardiovasc Surg 2011;141:881-7)

Despite the liberal use of stapling devices, intraoperative pulmonary air leakage occurs in $75 \%$ of patients after elective pulmonary resection. ${ }^{1}$ Patients with prolonged air leaks are at risk for serious complications, such as empyema. Prolonged air leaks might necessitate pleurodesis or even reoperation. ${ }^{2}$ Approaches to decrease the intensity and duration of air leaks include a variety of techniques and sealants. A Cochrane review that evaluated the effectiveness of sealants in preventing or reducing postoperative air leaks after pulmonary resection concluded that surgical sealants reduce postoperative air leaks. ${ }^{3}$ However, the definitive role of sealants in air leak treatment after lung surgery remains unclear. Most of the reports were single-center studies, and in

\footnotetext{
From University Hospitals Leuven, ${ }^{\mathrm{a}}$ Leuven, Belgium; Otto Wagner Hospital, ${ }^{\mathrm{b}}$ Vienna, Austria; VU-Medisch Centrum, ${ }^{\mathrm{c}}$ Amsterdam, The Netherlands; Universitätsklinik-Landeskrankenhaus Innsbruck, ${ }^{\mathrm{d}}$ Innsbruck, Austria; Papworth Hospital NHS Foundation Trust, ${ }^{e}$ Cambridge, United Kingdom; Universitaets Spital Zurich, ${ }^{\mathrm{f}}$ Zurich, Switzerland; and Hôpital Erasme, ${ }^{\mathrm{g}}$ Brussels, Belgium.

Disclosures: The study was funded by Covidien. Dr P. De Leyn has a consultancy agreement with Covidien.

Received for publication May 1, 2010; revisions received July 17, 2010; accepted for publication Sept 24, 2010; available ahead of print Nov 22, 2010.

Address for reprints: Paul De Leyn, MD, PhD, University Hospitals Leuven, Herestraat 49, 3000 Leuven, Belgium (E-mail: Paul.deleyn@uz.kuleuven.ac.be).

$0022-5223 / \$ 36.00$

Copyright (C) 2011 by The American Association for Thoracic Surgery

doi:10.1016/j.jtcvs.2010.09.019
}

many the sealant was used to prevent rather than treat air leaks because few patients with air leaks were randomized.

PleuraSeal (Covidien, Bedford, Mass) is a synthetic, polyethylene glycol (PEG)-based hydrogel sealant intended for use in elective pulmonary resections as an adjunct to standard closure techniques. The sealant is fully synthetic, more than $90 \%$ water, and has no human- or animal-derived products. When applied, it forms an effective barrier that is tissue compliant, tissue adherent, and lubricious. The material is absorbed in approximately 4 to 8 weeks, which is sufficient time to allow for healing. This study evaluated the air-sealing efficacy of PleuraSeal on alveolar air leaks after open lobectomy or segmentectomy.

\section{MATERIALS AND METHODS}

This was a prospective, multicenter, randomized, single-blind study. $\mathrm{Pa}$ tients older than 18 years who were scheduled for elective lobectomy or anatomic segmental resection by means of open thoracotomy were eligible for inclusion. Patients were screened within 6 weeks of the operation. Preoperative laboratory values could not exceed $1.5 \mathrm{mg} / \mathrm{dL}$ serum bilirubin, $120 \mathrm{IU} / \mathrm{L}$ alkaline phosphatase, $1.5 \mathrm{mg} / \mathrm{dL}$ creatinine, and 10,800/. $\mathrm{mm}^{3}$ white blood cell count. Further preoperative exclusion criteria were a documented history of bleeding disorders, compromised immune system, prior ipsilateral thoracotomy, active systemic or pulmonary infection, uncontrolled diabetes, and chronic steroid therapy ( $>4$ weeks). Female patients with childbearing potential required a negative pregnancy test result before inclusion. All patients were required to provide written informed consent. The study protocol was approved by the ethics committees of all the 


\section{Abbreviation and Acronym \\ PEG = polyethylene glycol}

centers, and the study conduct conformed to the guidelines outlined in the Declaration of Helsinki and good clinical practices.

The study was performed at 8 tertiary care medical centers in Europe: University Hospital Leuven (Leuven, Belgium), Otto Wagner Hospital (Vienna, Austria), VU-Medisch Centrum (Amsterdam, The Netherlands), Universitätsklinik-Landeskrankenhaus Innsbruck (Innsbruck, Austria), University Hospital Zurich (Zurich, Switzerland), Hôpital Erasme (Brussels, Belgium), Papworth Hospital (Cambridge, United Kingdom), and Medical Centre Rotterdam Zuid (Rotterdam, The Netherlands). This last center was not able to enroll any patients. All participating surgeons were qualified thoracic surgeons. At an investigator meeting, the protocol was discussed, and investigators were trained to use the sealant.

The primary end point was the proportion of patients remaining air leak free from the time of skin closure to hospital discharge. Secondary end points were the proportion of patients with successful intraoperative air leak sealing, time from skin closure to last observable air leak, duration of chest tube drainage, and length of hospitalization. All serious adverse events, treatment-related events, unanticipated adverse device effects, and predefined complications were reported.

All pulmonary resections were performed according to the institutional standard-of-care procedures. The fissures were opened in a nonthoracoscopic way by opening the fissure on the artery and then stapling or suturing the incomplete fissure.

After hemostasis was achieved and standard lung tissue closure was completed to the investigator's satisfaction, eligible patients underwent an air leak assessment by means of lung submersion leak testing. Warm sterile saline solution or water was instilled into the thorax in a sufficient quantity to allow for submersion of the cut or dissected lung surfaces. Although mechanical ventilation was maintained with an end-inspiratory airway pressure of approximately 20 to $25 \mathrm{~cm} \mathrm{H}_{2} \mathrm{O}$, all sites of surgical dissection and surgical manipulation were assessed for leaks and graded as reported by Macchiarini and colleagues. ${ }^{4}$ The location, type (staple line, suture line, area of adhesion, and area of dissection), and grade of each air leak were recorded.

During the operation, patients were deemed ineligible for further participation if they underwent pneumonectomy or sleeve resection, if they had severe adhesions, or if hemostasis could not be obtained. Patients with simple adhesions limited to the lobe that had to be removed were included. Patients without intraoperative air leaks were ineligible for randomization.

The flow diagram of the study is shown in Figure 1. Patients who presented with an intraoperative air leak were allowed to be treated with additional standard closure techniques before randomization if the investigator determined it feasible. Patients were then randomly assigned on a 1:1 basis to either the pleural sealant group or control group. Randomization was blocked by investigative site. Randomization was also stratified by a combined preoperative/intraoperative air leak risk assessment score (high-risk score $[>5]$ versus low-risk score $[\leq 5])$ to ensure balance between the 2 treatment groups. This risk assessment score was based on preoperative and intraoperative parameters (Tables 1 and 2).

Before study initiation, a treatment randomization scheme was generated, and randomization envelopes were provided to each site. Patients were randomized within their risk stratum by opening the next sealed envelope (labeled either high risk or low risk) in the operating room.

After resection, 2 chest drains were inserted. Postoperatively, chest tubes were run on $20 \mathrm{~cm} \mathrm{H}_{2} \mathrm{O}$ suction for up to 18 hours and then switched to a water seal. The chest drainage system was examined by trained staff at

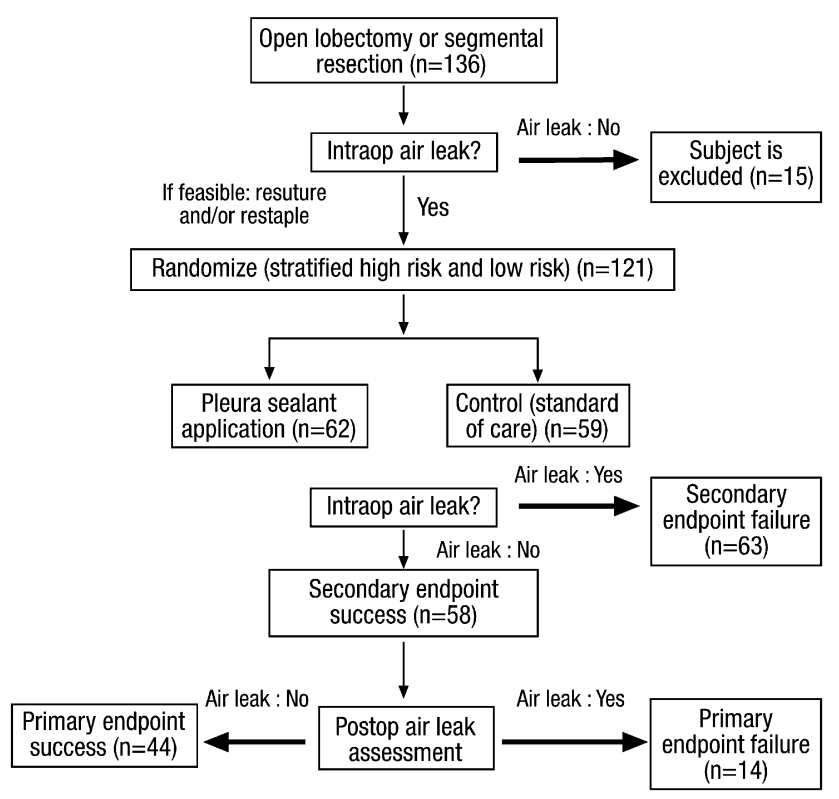

FIGURE 1. Flow diagram of the multicenter pleural sealant study.

12-hour intervals. Postoperative air leaks were defined as the presence of a single air bubble in the chest drains during the course of normal or forced expiration (coughing). The chest tubes were removed when there was no evidence of an air leak and the drainage was less than $300 \mathrm{~mL}$ in a $24-$ hour period. Chest radiographs were taken on the first postoperative day, within 8 hours after chest tube removal, and at discharge. Vital signs and renal and hepatic function were assessed immediately after the operation and at the follow-up evaluation 30 days postoperatively.

All statistical tests were 2-sided at the 5\% significance level, unless otherwise indicated. The statistical analysis was performed with SAS software, version 9.1 or higher (SAS Institute, Inc, Cary, NC). The primary effectiveness end point was defined as the proportion of patients remaining air leak free from the time of skin closure to hospital discharge. These proportions were determined and compared with a 2-sided Fisher's exact test. The time from skin closure to the last observable air leak (in hours) was evaluated. The Kaplan-Meier method was used to obtain estimated median time to leak-free status, and the log-rank test was used to compare the 2 treatments. The median duration of chest tube drainage and hospitalization was compared by using the 2-sample $t$ test.

TABLE 1. Preoperative criteria for randomization: High versus low risk

\begin{tabular}{lcc}
\hline \multicolumn{1}{c}{ Preoperative criteria } & Score if absent & Score if present \\
\hline COPD $1\left(\mathrm{FEV}_{1} \geq 80\right)$ & 0 & 1 \\
$\mathrm{COPD} 2\left(\mathrm{FEV}_{1} 50-80\right)$ & 0 & 2 \\
$\mathrm{COPD} 3\left(\mathrm{FEV}_{1}<30-50\right)$ & 0 & 3 \\
$\mathrm{COPD} 4\left(\mathrm{FEV}_{1}<30\right)$ & 0 & 4 \\
$\mathrm{FEV}_{1} / \mathrm{FVC} \%<65 \%$ & 0 & 1 \\
Smoking (ever as a habit) & 0 & 1 \\
Emphysema & 0 & 1 \\
Preoperative chemotherapy* & 0 & 1 \\
Preoperative radiation therapy* & 0 & 1 \\
\hline
\end{tabular}

$\overline{C O P D \text {, Chronic obstructive pulmonary disease; } F E V_{l} \text {, forced expiratory volume in } 1}$ second; $F V C$, forced vital capacity. *Patients treated with neoadjuvant therapy/surgery protocol. 
TABLE 2. Intraoperative criteria for randomization: High versus low risk

\begin{tabular}{lllc}
\hline Intraoperative criteria & Score $=\mathbf{0}$ & Score $=\mathbf{1}$ & Score $=\mathbf{2}$ \\
\hline Adhesions & Absent & Present (any) & NA \\
Tissue & Normal & Fragile* & NA \\
Extent of operation & Typical & Extensive $\dagger$ & NA \\
No. of leak sites & $1-2$ & $3-6$ & $>6$
\end{tabular}

$N A$, Not applicable. *Extensive bullous disease; fibrotic noncompliant tissue; thin parenchyma, low blood vessel density, or both; or torn lung. †Patient requires complete intrapleural resection of adhesions or extensive intrafissural dissection in subjects with incomplete pulmonary fissures or requires surgical resection of more than 1 lobe (eg, lobectomy and wedge resection or bilobectomy).

For the purpose of estimating sample size, the success rates for the sealant and control groups were assumed to be $0.40(40 \%)$ and $0.15(15 \%)$, respectively. Based on the anticipated tissue closure success rates and assuming a 1:1 (pleura; sealant/control) randomization ratio, 56 patients per treatment were required to achieve $80 \%$ power $(\alpha=.05$, 2-tailed, Fisher's exact test), resulting in a total of 112 patients. To account for approximately $6 \%$ anticipated patient withdrawals, an additional 8 patients were to be enrolled, for a total of 120 randomized patients, with approximately 60 per group.

\section{RESULTS}

Between January 28, 2008, and October 21, 2008, 161 patients consented to potential study participation, of whom 121 were randomized to the sealant group $(n=62)$ or the control group $(n=59)$. Of these, 120 patients $(61$ in the sealant group and 59 in the control group) completed the 30-day follow-up. Among the 40 nonrandomized patients, 5 did not meet the preoperative eligibility criteria after providing informed consent. The other 35 did not meet the intraoperative eligibility criteria. The main reasons for intraoperative exclusion were absence of an intraoperative air leak (15/156) or surgical procedures other than open lobectomy or anatomic segmentectomy (21/156).

Table 3 shows the baseline demographic and intraoperative characteristics. Overall, the sealant and control groups were well balanced. The indication for pulmonary resection was lung cancer in most of the cases $(98.4 \%)$. In $98 \%$ of patients, an open lobectomy was performed. In $62 \%$ of patients, the lobectomy was on the right side, with upper lobectomy the most frequent. Estimated total length of staples and sutures was similar between groups. Additional prerandomization standard closure techniques were staples in $9 \%$ (pleural sealant group) and 3.4\% (control group) and sutures in $7.3 \%$ (pleural sealant group) and $6.8 \%$ (control group). Other sealants were not used.

The mean duration of surgical intervention was not statistically different between the sealant and control groups: 2.5 hours (range, 1.4-4.6 hours) versus 2.35 hours (range, $1.0-4.2$ hours), respectively.

The mean total preoperative risk score was significantly different between groups (sealant, 3.0; control, 2.6; $P=.039$ ), which suggests that the sealant group was a higher-risk population. There was no statistical difference between groups in
TABLE 3. Baseline and intraoperative patients' characteristics

\begin{tabular}{|c|c|c|c|}
\hline Characteristics & $\begin{array}{l}\text { Pleural sealant } \\
\text { group }(n=62)\end{array}$ & $\begin{array}{c}\text { Control } \\
\text { group } \\
(\mathbf{n}=\mathbf{5 9})\end{array}$ & $\begin{array}{c}P \\
\text { value* }^{*} \\
\end{array}$ \\
\hline Age (y) & & & .463 \\
\hline Mean (SD) & $61.5(9.1)$ & $62.8(10.8)$ & \\
\hline Range (minimum-maximum) & $35-77$ & $25-81$ & \\
\hline Sex, no. $(\%)$ & & & .710 \\
\hline Female & $26(41.9)$ & $22(37.3)$ & \\
\hline Male & $36(58.1)$ & $37(62.7)$ & \\
\hline BMI $\left(\mathrm{kg} / \mathrm{m}^{2}\right)$ & & & .563 \\
\hline Mean (SD) & $25.86(4.73)$ & $26.35(4.55)$ & \\
\hline Range (minimum-maximum) & $17.7-41.6$ & $18.8-41.0$ & \\
\hline Nicotine use, no. $(\%)$ & & & .719 \\
\hline History & $31(50.0)$ & $34(57.6)$ & \\
\hline Current & $22(35.5)$ & $17(28.8)$ & \\
\hline Ethnic origin, no. $(\%)$ & & & .553 \\
\hline White & $61(98.4)$ & $55(93.2)$ & \\
\hline Other & $1(1.6)$ & $4(6.8)$ & \\
\hline \multicolumn{4}{|l|}{ Indication for operation, no. (\%) } \\
\hline Primary lung cancer & $62(100.0)$ & $57(96.6)$ & .236 \\
\hline Other & $0(0.0)$ & $2(3.4)$ & \\
\hline \multicolumn{4}{|l|}{$\begin{array}{r}\text { Concomitant pulmonary } \\
\text { diagnosis, no. }(\%)\end{array}$} \\
\hline None & $27(43.5)$ & $34(57.6)$ & .147 \\
\hline Emphysema & $16(25.8)$ & $9(15.3)$ & .181 \\
\hline Asthma & $3(4.8)$ & $1(1.7)$ & .619 \\
\hline Silicosis & $1(1.6)$ & $2(3.4)$ & .613 \\
\hline COPD & $29(46.8)$ & $20(33.9)$ & .195 \\
\hline Chronic bronchitis & $2(3.2)$ & $1(1.7)$ & 1.000 \\
\hline \multicolumn{4}{|l|}{$\begin{array}{l}\text { Previous pulmonary } \\
\text { therapy, no. }(\%)\end{array}$} \\
\hline Radiation therapy & $5(8.1)$ & $2(3.4)$ & .440 \\
\hline Chemotherapy & $10(16.1)$ & $4(6.8)$ & .154 \\
\hline $\begin{array}{l}\text { Total risk score (preoperative } \\
\text { and intraoperative) }\end{array}$ & $3.9 \pm 2.0$ & $3.4 \pm 1.6$ & .160 \\
\hline Type of procedure $\dagger$ & & & 1.000 \\
\hline Lobectomy & $61(98.4)$ & $58(98.3)$ & \\
\hline Segmentectomy & $1(1.6)$ & $1(1.7)$ & \\
\hline Resection location, no. (\%) & & & .458 \\
\hline Left lung & $21(33.9)$ & $24(40.7)$ & .755 \\
\hline Right lung & $41(66.1)$ & $35(59.3)$ & .234 \\
\hline
\end{tabular}

$B M I$, Body mass index; $C O P D$, chronic obstructive pulmonary disease. $* P$ value from Fisher's exact test for categorical variables and from the 2-sample $t$ test for continuous variables. $\dagger$ A patient can have more than 1 procedure, and therefore the percentages might sum to more than $100 \%$.

the intraoperative risk score or the total combined risk score (preoperative and intraoperative). According to the risk stratification performed, $86 \%$ of patients were scored lower risk and $14 \%$ were scored higher risk.

Grade 1 intraoperative air leaks were observed before randomization in $26 \%$ of the sealant group versus $44 \%$ of the control group. Consequently, grade 2 and 3 air leaks were observed in $74 \%$ of the sealant group versus $56 \%$ of the control group. These differences were not statistically significant $(P=.077)$. In the pleural sealant group $44.8 \%$ 
of the air leaks were at the newly created fissure compared with $46.6 \%$ in the control group.

\section{Primary End Point}

In the sealant group $41.9 \%$ of patients remained air leak free until discharge versus $30.5 \%$ in the control group $(P=.257)$. The pleural sealant was found to be more effective in sealing grade 2 and 3 air leaks than control treatment ( $43.5 \%$ success vs $15.2 \%$ success, respectively; $P=.013$ ). The difference between treatments on grade 1 leaks was not significant (Figure 2).

\section{Secondary End Points}

The pleural sealant effectively sealed intraoperative air leaks, as shown in Figure 3. Overall, significantly more patients had successful intraoperative sealing after pleural sealant application than patients who received the control standard of care $(71.0 \%$ vs $23.7 \%, P<.001)$. In the lowrisk population the pleural sealant stopped air leaks in significantly more patients than control standard of care ( $70.6 \%$ vs $24.5 \%, P<.001)$. In the high-risk population the pleural sealant was more effective than control standard of care, but the difference was just short of statistical significance $(72.7 \%$ vs $16.7 \%, P=.050)$.

Before pleural sealant application, 16 (25.8\%) patients had grade 1 air leaks, $42(67.7 \%)$ had grade 2 air leaks, and $4(6.5 \%)$ had grade 3 air leaks. Application of the pleural sealant completely sealed the air leaks in 44 (71\%) patients; in $14(22.6 \%)$ patients the air leak diminished to grade 1 , and in $4(6.5 \%)$ patients it decreased to grade 2 .

The median time from skin closure to the last observable air leak was shorter in patients treated with the pleural sealant than in those who received standard of care, but the difference was not statistically significant (6 vs 30 hours, $P=.790$ ). The median duration of chest tube drainage was not statistically different between the sealant and control groups (93.7 hours [range, 22.7-838.9 hours] vs 94.1 hours [range, 17.7-478.7 hours], $P=.559$ ).



FIGURE 2. Primary end point: percentage of patients with grade 1 and grade 2 or 3 air leak who remained air leak free until discharge in the pleural sealant and control groups.

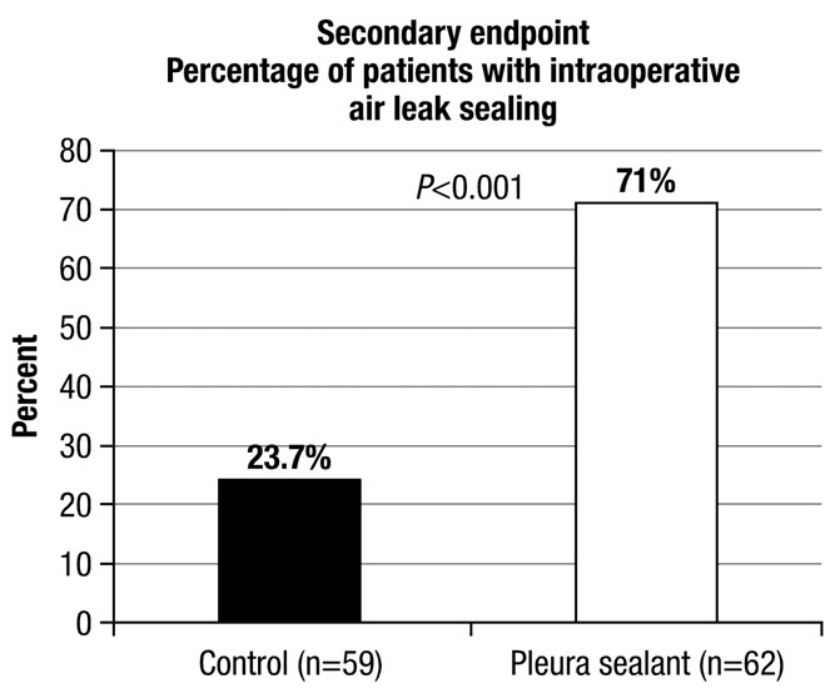

FIGURE 3. Percentage of patients with intraoperative air leak sealing in the pleural sealant and control groups.

The median length of hospitalization was not statistically different between the sealant and control groups ( 312 hours [range, 144-3144 hours] vs 288 hours [range, 120-2040 hours], $P=.292$ ). Persistent air leaks were the reason for a delayed hospital discharge in $4.8 \%$ of the pleural sealant group and $11.9 \%$ of the control group $(P=.303)$.

The incidence of predefined complications or serious adverse events was similar between the sealant and control groups $(35.5 \%$ vs $23.7 \%, P=.170)$, as shown in Tables 4 to 6 . There were no deaths. There were no treatmentrelated adverse events noted for either treatment group. The reported complications were not unexpected for the surgical procedure or the underlying cancer. No clinical or laboratory evidence of adverse events attributable to the application of the sealant was observed.

In the vast majority of patients, the lung was fully expanded at all postoperative time points. At discharge, the lung was fully expanded in $97.4 \%$ of the pleural sealant group and $97.3 \%$ of the control group. Lung expansion and residual space in patients with pneumothorax was comparable between groups.

\section{DISCUSSION \\ Air Leak Control}

Air leaks are a common problem after lobectomy for lung cancer and are the major cause of prolonged hospitalization. Prolonged air leak occurs in $15 \%$ of patients undergoing lobectomy. Although air leaks can heal conservatively, some patients will have empyema, might need a reintervention, or both. ${ }^{2}$ A study conducted by Brunelli and coworkers ${ }^{5}$ evaluated air leaks after lobectomy. On the first postoperative day, $28.8 \%$ of patients had air leaks. Prolonged air leak, defined as lasting more than 7 days, was present in $15.6 \%$ of patients, and $3.4 \%$ of patients still 
TABLE 4. Summary of reported events (safety population)

\begin{tabular}{|c|c|c|c|}
\hline Parameter & $\begin{array}{l}\text { Pleural sealant group } \\
\quad(\mathrm{n}=62), \text { no. }(\%)\end{array}$ & $\begin{array}{c}\text { Control group } \\
(\mathbf{n}=\mathbf{5 9}), \text { no. }(\%)\end{array}$ & $P$ value* \\
\hline Subjects with any predefined complication or SAE & $22(35.5)$ & $14(23.7)$ & .170 \\
\hline Subjects with any SAE & $16(25.8)$ & $11(18.6)$ & .388 \\
\hline Subjects with any predefined complication & $9(14.5)$ & $6(10.2)$ & .584 \\
\hline Subjects with any unanticipated adverse device effect & $0(0.0)$ & $0(0.0)$ & - \\
\hline Subjects with any treatment-related reported event & & & - \\
\hline Yes & $0(0.0)$ & $0(0.0)$ & - \\
\hline No & $56(90.3)$ & $57(96.6)$ & .274 \\
\hline Unable to determine & $6(9.7)$ & $2(3.4)$ & .274 \\
\hline
\end{tabular}

$S A E$, Serious adverse event. $* P$ value based on Fisher's exact test.

had persistent air leak after 1 month. Patients with prolonged air leak had significantly higher morbidity compared with those without prolonged air leak, with a significantly higher incidence of empyema and pneumonia.

TABLE 5. Serious adverse events (subject level)

\begin{tabular}{|c|c|c|c|}
\hline $\begin{array}{c}\text { System organ } \\
\text { class/preferred term }\end{array}$ & $\begin{array}{c}\text { Pleural sealant } \\
\text { group }(n=62), \\
\text { no. }(\%) \\
\end{array}$ & $\begin{array}{l}\text { Control group, } \\
(\mathbf{n}=\mathbf{5 9}), \\
\text { no. }(\%) \\
\end{array}$ & $\begin{array}{c}P \\
\text { value* } \\
\end{array}$ \\
\hline Infections and Infestations & $5(8.1)$ & $3(5.1)$ & .718 \\
\hline Empyema & $2(3.2)$ & $0(0.0)$ & \\
\hline Pneumonia & $2(3.2)$ & $1(1.7)$ & \\
\hline Bronchopneumonia & $0(0)$ & $1(1.7)$ & \\
\hline Wound infection & $1(1.6)$ & $1(1.7)$ & \\
\hline $\begin{array}{l}\text { Respiratory, thoracic, } \\
\text { and mediastinal disorders }\end{array}$ & $9(14.5)$ & $5(8.5)$ & .397 \\
\hline $\begin{array}{l}\text { Acute respiratory } \\
\text { distress syndrome }\end{array}$ & $1(1.6)$ & $0(0.0)$ & \\
\hline Atelectasis & $0(0.0)$ & $1(1.7)$ & \\
\hline Bronchopleural fistula & $1(1.6)$ & $0(0.0)$ & \\
\hline Pleural effusion & $1(1.6)$ & $0(0.0)$ & \\
\hline Pneumothorax & $5(8.1)$ & $1(1.7)$ & \\
\hline Hydropneumothorax & $1(1.6)$ & $2(3.4)$ & \\
\hline Pulmonary embolism & $0(0.0)$ & $1(1.7)$ & \\
\hline Emphysema & $1(1.6)$ & $0(0.0)$ & \\
\hline Cardiac disorders & $2(3.2)$ & $1(1.7)$ & 1.000 \\
\hline Cardiac arrest & $0(0.0)$ & $1(1.7)$ & \\
\hline Cardiac failure chronic & $1(1.6)$ & $0(0.0)$ & \\
\hline Ventricular fibrillation & $1(1.6)$ & $0(0.0)$ & \\
\hline Nervous system disorders & $1(1.6)$ & $0(0.0)$ & 1.000 \\
\hline Ischemic stroke & $1(1.6)$ & $0(0.0)$ & \\
\hline $\begin{array}{c}\text { Skin and subcutaneous } \\
\text { tissue disorders }\end{array}$ & $1(1.6)$ & $0(0.0)$ & 1.000 \\
\hline Subcutaneous emphysema & $1(1.6)$ & $0(0.0)$ & \\
\hline Vascular disorders & $0(0.0)$ & $1(1.7)$ & .488 \\
\hline Peripheral ischemia & $0(0.0)$ & $1(1.7)$ & \\
\hline $\begin{array}{l}\text { General disorders and } \\
\text { administration site } \\
\text { conditions }\end{array}$ & $2(3.2)$ & $2(3.4)$ & 1.000 \\
\hline Fatigue & $0(0.0)$ & $2(3.4)$ & \\
\hline Pain & $2(3.2)$ & $0(0.0)$ & \\
\hline
\end{tabular}

Note: A patient can have more than 1 event. If a patient had multiple occurrences of the same serious adverse event, only the first occurrence was counted. ${ }^{*} P$ value based on Fisher's exact test.
Preventing air leakage is important for optimal outcomes and is controlled in part by meticulous thoracic surgical techniques, pleural tenting in upper lobectomy, and use of buttressed staplers in emphysematous tissue. ${ }^{6}$ Standard methods of closure, including sutures and staples, have the disadvantage of causing further trauma to the lung tissue, which can increase the air leak severity.

\section{Surgical Sealants}

There has been great interest in the use of surgical sealants (glue) to seal air leaks after lung resection. The ideal lung sealant material needs to be sufficiently strong and adherent to withstand pressures of 30 to $40 \mathrm{~cm} \mathrm{H}_{2} \mathrm{O}$ that are normally present in inflated lungs. A sealant material should also be flexible and compliant to accommodate lung volume changes. Sealants should bond rapidly to lung tissue and be unaltered by underlying blood or moisture. The sealant needs to be locally nonirritating, systemically nontoxic, and nonantigenic. Lastly, the ideal sealant should be readily available in the operating room and easy to use.

Recently, a new synthetic tissue sealant has been developed with mechanical characteristics approximating these qualities. The pleural sealant used in this study rapidly polymerizes (within 3 seconds) to form a biocompatible absorbable PEG hydrogel. The hydrogel is simple to prepare and easy to apply. Because it is synthetic, the pleural sealant has no potential for transmitting blood-borne pathogens.

TABLE 6. Rates of predefined complications (safety population)

\begin{tabular}{lccr}
\hline \multicolumn{1}{c}{ Complication } & $\begin{array}{c}\text { Pleural sealant } \\
\text { group }(\mathbf{n}=\mathbf{6 2}), \\
\text { no. (\%) }\end{array}$ & $\begin{array}{c}\text { Control group } \\
(\mathbf{n = 5 9 )} \text {, no. (\%) }\end{array}$ & $\begin{array}{c}\boldsymbol{P} \\
\text { value* }^{*}\end{array}$ \\
\hline Colitis/gastroenteritis & $3(4.8)$ & $0(0.0)$ & .244 \\
Urinary tract infection & $1(1.6)$ & $0(0.0)$ & 1.000 \\
Pleural empyema & $2(3.2)$ & $0(0.0)$ & .496 \\
Wound infection & $2(3.2)$ & $1(1.7)$ & 1.000 \\
Atrial fibrillation & $2(3.2)$ & $4(6.8)$ & .432 \\
Pulmonary embolism & $0(0.0)$ & $1(1.7)$ & .488 \\
\hline
\end{tabular}

Note: A patient can have more than 1 event. If a patient had multiple occurrences of the same complication, only the first occurrence was counted. Predefined complications that are serious adverse events are included. $* P$ value based on Fisher's exact test. 
Moreover, the PEG polymer is nonimmunogenic, and its high water content results in a gel with a low durometer value and favorable elastic properties that is ideal for lung applications.

\section{Air Leak Clinical Trials}

A recent Cochrane study evaluated the use of sealants for preventing air leaks after pulmonary resection. ${ }^{3}$ Between 1990 and 2008, 16 trials with 1642 randomized patients were included. Several types of sealants were used. In 6 trials postoperative air leaks were significantly reduced. ${ }^{7-12}$ Three trials showed a significant reduction in time to chest drain removal. $^{7,10,13}$ In 3 trials there was a significant reduction in length of hospital stay. ${ }^{10,13,14}$ However, these trials differed in several ways. Only 4 trials were multicenter studies. ${ }^{9,12,14,15}$ In only 6 trials were patients with intraoperative air leaks randomized. ${ }^{8,10,12-14,16}$ In other trials staple lines and cut surfaces of lung parenchyma were routinely covered with the sealant regardless of the presence of air leaks.

Since the Cochrane study, 1 study on the use of sealants for air leaks has been published. ${ }^{17} \mathrm{~A}$ single-center study evaluated the role of Coseal Surgical Sealant (PEG; Baxter BioSurgery, Deerfield, Ill) after wedge resection/lobectomy/segmentectomy in patients with grade 2 and 3 air leaks. Intraoperative air leaks were significantly more sealed, and there was a significant reduction in air leak duration. However, there was no effect on chest drain duration or hospitalization.

Results from single-center studies cannot always be repeated in multicenter studies because many confounding factors can interfere and standard practices vary in each institution. A single-center study evaluating the role of Tachosil (equine-derived collagen patch coated with human fibrinogen and thrombin; Nycomed, Zurich, Switzerland, and Baxter BioSurgery) found no significant effect on the percentage of air leak-free patients on the first and second postoperative days. However, a significant reduction in time to chest drain removal and hospitalization time was found. ${ }^{13}$ In a multicenter study the use of the same sealant after lobectomy had no significant effect on chest drain duration or hospital stay. ${ }^{12}$

Air leaks can be measured in different ways. Nowadays, systems with digital airflow sensors are available that are more accurate in measuring postoperative air leakage. One study found no significant effect on the percentage of air leak-free patients on the first and second postoperative days after application of Tachosil. ${ }^{13}$ However, when postoperative air leakage was measured with the digital mass airflow sensor device, a significant reduction of air leak volume was noted.

\section{Pleural Sealant Multicenter European Study}

In this prospective European study the use of the pleural sealant for air leak treatment after pulmonary resection was analyzed. The majority of patients underwent lobectomy for lung cancer. Patients were stratified into high-risk or lowrisk groups according to well-defined preoperative and intraoperative risk factors. In $71 \%$ of treated patients, the pleural sealant completely sealed intraoperative air leaks, and in the remaining patients intraoperative air leaks became less severe. The sealant effect was statistically significant compared with that seen in the control group.

Postoperatively, $41.9 \%$ of sealant-treated patients and $30.5 \%$ of patients receiving standard care remained air leak free, but this effect did not reach statistical significance. Among patients with grade 2 and 3 intraoperative air leaks, significantly more sealant-treated patients than control patients remained air leak free until discharge $(43.5 \%$ vs $15.2 \%, P=.013)$. There was a clear trend toward reduced duration of air leak in the pleural sealant group (6 hours) compared with the control group (30 hours), but statistical significance was not attained. We observed no significant effect on chest drain or hospitalization durations. However, the length of hospitalization was highly variable by site.

Somewhat to our surprise, the standard care control group had a higher-than-expected rate of intraoperative (23.7\%) and postoperative $(30.5 \%)$ air leak control. The choice of a $15 \%$ success rate for the primary end point for the control group was based on the best available information at the time of the design of the study. A study by Allen and associates ${ }^{14}$ had reported that $14 \%$ of control patients receiving the standard of care remained leak free after pulmonary resection. The choice of a $40 \%$ success rate for the treatment group was based on available animal data and turned out to be reasonably accurate. The lack of statistical significance for the primary end point might well be due to insufficient statistical power. With the planned sample size of 60 subjects per treatment group, the statistical power was only $19.9 \%$ to reject the null hypothesis of no difference in the true treatment percentages using a 2-sided Fisher's exact test, if the true treatment percentages were as observed in this study. To obtain $80 \%$ power would have required a much larger study with 295 subjects per treatment group.

There were no specific complications or morbidity that appeared to result from the use of the sealant. There was no difference noted in the presence of pneumothorax or in the expansion of the remaining lung. The pleural sealant appears to be safe for patients and is easy for surgeons to apply.

We believe that the strengths of this study are that it is a multicenter study and that all patients had open lobectomy or segmental resection with intraoperative proof of air leaks that were not suitable for correction by means of resuturing or restapling. A limitation of our study is the interobserver variability in assessing the presence of an air leak. By using digital chest drainage units with airflow sensors, the interobserver variability might be even more reduced, and this might be useful for future studies. 
Our study also shows that in Europe hospital stay after lobectomy is not primarily determined by the presence of air leaks. Other (medical, cultural, and social) reasons seem to have a major effect on length of hospital stay. However, because health care financing has become more and more care-program driven with a fixed payment per pathology, the evolution of shorter hospitalization after pulmonary resection is to be expected in Europe. At that time, it is likely that duration of air leakage will have a significant effect on hospitalization time, and sealants like the pleural sealant tested in this study can play an important role in achieving that goal.

In this multicenter European study the use of the pleural sealant significantly reduced intraoperative air leaks after lobectomy. In patients with clinically significant air leaks (grade 2 and 3), significantly fewer patients had postoperative air leaks when treated with the pleural sealant. However, this did not result in a significantly shorter duration of chest drain use and length of hospital stay. We conclude that the pleural sealant used in this study is easy to use, safe, and effective in treating patients with clinically relevant air leaks after pulmonary resection.

\section{References}

1. Serra-Mitjans M, Belda Sanchis J, Rami-Porta R. Surgical sealant for preventing air leaks after pulmonary resection in patients with lung cancer. Cochrane Database Syst Rev. 2005;(3):CD003051.

2. Liberman M, Muziknasky A, Cameron D, Wain JC, Donahue DM, Allan JS, et al. Incidence and risk factors of persistant air leak after major pulmonary resection and use of chemical pleurodesis. Ann Thorac Surg. 2010;89: 891-8.

3. Belda Sanchis J, Serra-Mitjans M, Iglesias Sentis M, Rami R. Surgical sealant for preventing air leaks after pulmonary resections in patients with lung cancer. $\mathrm{Co}$ chrane Database Syst Rev. 2010;(1):CD003051.
4. Macchiarini P, Wain J, Almy S, Darteville P. Experimental and clinical evaluation of a new synthetic, absorbably sealant to reduce air leaks in thoracic operations. J Thorac Cardiovasc Surg. 1999;117:751-8.

5. Brunelli A, Montevardo M, Borri A, Salati M, Sabbatini A, Fianchini A. Predictors of prolonged air leak after pulmonary lobectomy. Ann Thorac Surg. 2004;77: 1205-10.

6. Brunelli A, Refai MA, Monteverde M, Borri A, Salati M, Sabbatini A, et al. Pleural tent after upper lobectomy: A randomized study of efficacy and duration of effect. Ann Thorac Surg. 2002;74:1958-62.

7. Fabian T, Federico JA, Ponn RB. Fibrin glue in pulmonary resection: a prospective randomized, blinded study. Ann Thorac Surg. 2003;75:1587-92.

8. Porte HL, Jany T, Akkad R, Conti M, Gillet PA, Guidat A, et al. Randomized controlled trial of a synthetic sealant for preventing alveolar air leaks after lobectomy. Ann Thorac Surg. 2001;71:1618-22.

9. Wain JC, Kaiser LR, Johnstone DW, Yang SC, Wright CD, Friedberg JS, et al Trial of a novel synthetic sealant in preventing air leaks after lung resection. Ann Thorac Surg. 2001;71:1623-9.

10. Tansley P, Al-Mulhim F, Lada G, Goldstraw P. A prospective, randomized, controlled trial of the effectiveness of BioGlue in treating alveolar air leaks. J Thorac Cardiovasc Surg. 2006;132:105-12.

11. Droghetti A, Shiavini A, Muriana P, Folloni A, Picarone M, Bonadiman C, et al. A prospective randomized trial comparing completion technique of fissures for lobectomy: stapler versus precision dissection and sealant. J Thorac Cardiovasc Surg. 2008;136:383-91.

12. Marta GM, Facciolo F, Ladegaard L, Dienemann H, Csekeo A, Rea F, et al Tachosil vs. standard surgical treatment for air leakage in pulmonary lobectomy. Interact Cardiovasc Thorac Surg. 2008;7:(suppl 2):168-P.

13. Anegg U, Lindenmann J, Matzi V, Smolle J, Maier A, Smolle-Jüttner F. Efficiency of fleece-bound sealing (Tachosil) of air leaks in lung surgery: a prospective randomized trial. Eur J Cardiothorac Surg. 2007;31:198-202.

14. Allen MS, Wood ED, Hawkinson RW, Harpole DH, McKenna RJ, Walsh GL, et al. Prospective randomized study evaluating a biodegradable polymeric sealant for sealing intraoperative air leaks that occur during pulmonary resection. Ann Thorac Surg. 2004;77:1792-801.

15. Lang G, Csekeö A, Stamatis G, Lampl L, Hagman L, Marta GM, et al. Efficacy and safety of topical application of human fibrinogen/thrombin-coated collagen patch (TachoComb) for treatment of air leakage after standard lobectomy. Eur J Cardiothorac Surg. 2004;25:160-6.

16. Wong K, Goldstraw P. Effect of fibrin glue in the reduction of postthoracotomy alveolar air leak. Ann Thorac Surg. 1997;64:979-81.

17. D'Andrilli A, Andreetti C, Ibrahim M, Ciccone AM, Venuta F, Mansmann U, et al. A prospective randomized study to assess the efficacy of a surgical sealant to treat air leaks in lung surgery. Eur J Cardiothorac Surg. 2009;35:817-21. 